\title{
You keep using that word
}

\section{Slaying the dragon of reference desk statistics}

l 's that time of the year again. You know, that time when we are chasing down our IPEDS/ACRL numbers for the dreaded annual reports. Even with some helpful changes over the past few years, I continue to have questions about the value of at least some of the information we are all asked to provide. Some important trends can be clearly tracked. Circulation of print/physical materials has been declining steadily overall and continues to do so. Why? Ask a roomful of librarians and you will undoubtedly get many different explanations, and the reasons are a combination of many of those. Expenditures on those print/physical items is also declining in many academic libraries.

Are funds being reallocated to support digital services like streaming video? Are funds being used to support OER and open access initiatives? Have funds been eliminated from budgets so that reallocating money to support new services and resources is increasingly challenging (you may sense that this last example hits close to home for me)? Impossible to tell from the reports without checking notes if they have been added and are accessible.

I want to focus on lines 64 (Transactions), 65 (Consultations), and 67 (Virtual Reference Services) in the current ACRL Academic Library Statistics Survey. Line 67 is a subset of line 64 and the instructions are clear about what not to include. Our library now offers services in a way that makes figuring out what we should include not only difficult, but often impossible. And we did that intentionally.

About seven years ago, several librarians at Keene State College began a formal training program with some student staff so we could shift away from a Reference Desk staffed primarily by librarians to one staffed most of the time with students. Librarians were often "on call" and also available by appointment.
Over the course of several years, the information literacy librarian began a close collaboration with the director of the Writing Center (located in a different building). That led to an initiative to cross-train Writing Center tutors so that they could provide research help when needed during appointments, and some tutors also worked at the library's research help desk.

The Center for Writing is now the Center for Research \& Writing. We offer a 200-level course called "Tutoring for Research and Writing," which provides a pool of students who often go on to apply for tutor positions. All tutors work in the library and the center (and now also online both synchronously and asynchronously). Tutors also provide in-class workshops for faculty on a variety of topics.

So when a student comes into the library for help with a research question, sometimes the interaction is focused on research and sometimes it ends up in a conversation about writing. And many tutor appointments for writing support lead to productive conversations about writing and research.

Our tutors and their faculty team have been presenting at regional and international conferences about their work, and we are excited about helping students and faculty deepen their understanding of the connections between thinking and writing through the ways we provide academic support.

So how do we "count" these interactions? We are in the process of consolidating tracking software for drop-in/chat transactions, tutoring appointments, etc., so that we will use only one system to track

Celia Rabinowitz is dean of Keene State College's Mason Library, email: celia.rabinowitz@keene.edu 
interactions. Conversations about how to distinguish between research and writing inquiries leads us to more than just discussion about what we call something. Some remain relatively easy to identify. But some start out as one thing and end up an another or as both. Should we count all of them? Do we need to read chat transcripts so we can sort them into categories? Ask tutors to indicate whether an interaction is more about research than writing?

Library spaces have been morphing for a long time. Do we calibrate our gate count so it only counts people coming in to "use" the library but not as a coffee shop or for academic tutoring? The library remains a vital and important space on campus, and we support the wide range of collaborations we have with partners around campus.

Our information literacy librarian, in her frustration while collecting the numbers for the 2020 survey, exclaimed over a Zoom call, "That is so old school." I agree. We all know that the reference transaction numbers can be difficult to collect accurately. Are circulation desk staff logging inquiries? Are all of us who might respond to a question from someone directly by email remembering?
It is worth asking what we think these statistics represent, what they mean, what they demonstrate. They are one way to learn about which days and times are busiestat theseservice points. Wecanlearnabout thetypes of questionsweareasked, wecan read transcripts of hat sessions toassess howwell weare interacting with our users, wecan useinformation we retain to consider how wecan better support faculty. But most of this is about what we do, not how many times we do it.

For most (perhaps all) of us libraries, collecting numerical data is useful. We are working on ways to collect and analyze information that tells the story of what we are doing and helps us do that work better. That indudes some quantitative data: how many workshops our student tutors deliver, how many appointments, and how many chat and drop-in encounters. And the more we integrate our research and writing help services the less interested we are in categorizing interactions.

Instead we want to know more about what the interactions can teach us about how students think and write, and how we can continue to improve how we provide support. Not much of that is gleaned from the quantitative data. Every time I report our transaction data on thesurvey, I am tempted to add a note: "You keep using that word. I do not think it means what you think it means."-The Princess Bride

\section{Land the perfect job with help from ACRL!}

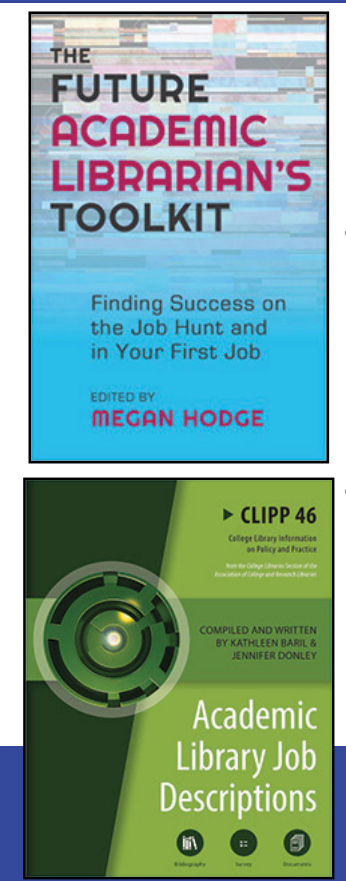

The Future Academic Librarian's

Toolkit: Finding Success on the Job

Hunt and in Your First Job

edited by Megan Hodge

Get the Job: Academic Library Hiring for the New

Librarian

by Meggan Press

Academic Library Job

Descriptions: CLIPP \#46

compiled by Kathleen Baril and

Jennifer Donley

All titles available from the ALA Store at:

https://www.alastore.ala.org 